\title{
EL TRATAMIENTO CIVIL DE LA MALA FE DEL ASEGURADO EN EL CONTRATO DE SEGURO*
}

Por Andrés E. Ordoñez Ordoñez**

\begin{abstract}
INTRODUCCION. REGIMEN GENERAL DE SANCION CIVIL AL DOLO DEL ASEGURADO EN EL CONTRATO DE SEGURO:
\end{abstract}

No es quizás la perspectiva del derecho privado la más indicada para abordar el tema del fraude en el seguro, puesto que en esta materia precisamente lo más importante en determinar la existencia del fraude y establecer las estadísticas, los indicadores, los mecanismos preventivos y los procedimientos indicados para identificar los casos de fraude y las técnicas más utilizadas para consumarlo.

Una vez determinada la existencia del fraude, pudiéramos decir que es fácil establecer sus consecuencias desde el punto de vista de la disciplina del contrato, en el entendido que las legislaciones generalmente tienen bien definida la manera de sancionar ese fraude y de impedir que produzca los frutos que persigue, independientemente de las consecuencias que se derivan del mismo en el plano del derecho penal.

Por tratarse en el caso del contrato de seguro de un contrato al que se reconoce por la doctrina más generalizada un carácter de especial buena fe, de ubérrima buena fe, no es extraño encontrar dentro de su regulación positiva continuas referencias al principio de la buena fe, no como un simple instrumento para juzgar el comportamiento de las partes frente al cumplimiento de sus obligaciones como es usual en cualquier contrato, sido para moderar objetivamente los efectos del mismo, alterando muchas veces los principios generales que rigen el negocio jurídico en beneficio del contratante de buena fe ante situaciones que en otros contratos supondrían, sin mayor discusión la privación de los efectos del acuerdo.

Pero frente a la prueba de la existencia de la mala fe, de la intención de fraude o de la malicia dirigida a obtener provecho por parte del asegurado, la reacción del ordenamiento es clara y se acomoda en líneas generales a los principios generales que rigen el contrato: la nulidad relativa del seguro, si esa mala fe influye en el momento en que se produce el intercambio de manifestaciones de voluntad que dan origen al contrato, en la medida en que configura un vicio de la voluntad, en este caso, el dolo, en ese momento de la celebración, la pérdida del derecho a la indemnización o la terminación del contrato, si esa mala fe se manifiesta en el comportamiento del asegurado posterior a la celebración del contrato o con motivo de la reclamación de la indemnización.

\footnotetext{
* Conferencia pronunciada por el Dr. Andrés E. Ordóñez Ordóñez el 27 de Octubre de 2.004, dentro del II Seminario Internacional de Fraude en Seguros. Este artículo fue presentado a la Revista el 24 de julio de 2005 y fue aceptado para su publicación por el Comité Editorial el día 12 de diciembre de 2005, previa revisión del concepto emitido por el árbitro evaluador.

${ }^{* *}$ Profesor de las Universidades Externado de Colombia y Javeriana en el área de Derecho de los Seguros.
} 
En la legislación colombiana, la presencia de mala fe o intención de fraude se sanciona específicamente frente a las siguientes situaciones:

1.- En la declaración del estado del riesgo: La nulidad relativa del contrato de seguro, con pérdida de la prima no devengada.

En otras legislaciones, se establecen consecuencias similares; tal ocurre en Francia, Italia y Argentina que contemplan también la sanción de nulidad relativa, mientras que en España se opta por dar al asegurador una facultad de resciliación del contrato; en los países de raigambre anglosajona, las soluciones son de parecido tenor y casi siempre van acompañadas de la sanción adicional para el tomador del seguro consistente en la pérdida de la prima que se haya devengado por el asegurador hasta el momento en que se produzca la cesación de los efectos del contrato, o en su totalidad como ocurre en el caso colombiano.

El articulo 1.058 del Código de Comercio, como es bien conocido, regula específicamente la nulidad relativa del contrato ante la presencia de inexactitud o reticencia en la declaración del estado del riesgo, en la medida en que una u otra hayan sido suficientes para determinar la voluntad del asegurado en el sentido de celebrar el contrato que no hubiera celebrado de haber conocido las reales circunstancias del riesgo, o en el sentido de celebrarlo en condiciones de onerosidad diferentes a las que hubieren sido pactadas en la misma situación, cuando dichas inexactitud o reticencia procede de error culpable o de dolo del tomador.

Características particulares de la normatividad colombiana a este respecto, contrastantes con lo que disponen otras legislaciones, son las siguientes;

a) La sanción del dolo eventual, que se traduce en aceptar la procedencia de la declaratoria de nulidad, aún frente al evento de que la reticencia o inexactitud en la declaración del estado del riesgo, no determinan la manifestación de voluntad del asegurador en cuanto al contrato mismo, sino en cuento a sus condiciones de onerosidad. En otras legislaciones y particularmente en la doctrina general del contrato, el dolo eventual no alcanza normalmente a generar la nulidad del contrato.

b) El no condicionamiento de la nulidad del contrato a la vinculación específica entre las causas que determinaron el siniestro y las circunstancias no declaradas o declaradas en forma inexacta por el tomador. En otras legislaciones, la nulidad del contrato solo procede cuando existe esa vinculación.

c) El hecho de que la formulación de un cuestionario por parte del asegurador para orientar al tomador en la declaración de asegurabilidad, no es condición necesaria para que proceda la sanción de la inexactitud o reticencia como si ocurre en otras legislaciones.

2.- En la declaración de valor asegurable. La nulidad relativa del contrato de seguro en caso de sobreseguro, igualmente con pérdida de la totalidad de la prima como sanción adicional, conforme a lo dispuesto por el artículo 1.091 del C. de Co. 


\section{REVIST@e - M ercatoria Volumen 4, Número 2 (2005)}

En este caso, aún cuando no exista intención de fraude, el asegurado sufre la consecuencia de perder la posibilidad de obtener el reembolso de las primas pagadas en exceso, cuando quiera que la situación de sobreseguro no se identifica y normaliza antes de la ocurrencia de un siniestro.

3.- La omisión en la carga de notificar al asegurador acerca de la agravación del estado del riesgo. Terminación del contrato con pérdida de la prima no devengada, en caso de mediar mala fe.

En este caso se penaliza en el artículo 1.060 del C.de Co. la intención dolosa que surge posteriormente a la celebración del contrato, y que se traduce precisamente en omitir el cumplimiento de la carga que corresponde al asegurado de notificar oportunamente al asegurador acerca de la agravación del estado del riesgo, con la sanción adicional de pérdida de la prima no devengada, ya que si no existe esa mala fe solo se produce la terminación del contrato a partir del momento en que se incurre en mora en el cumplimiento de la carga.

4.- El incumplimiento de la carga de notificar al asegurador sobre la coexistencia de seguros, con intención de fraude. La nulidad del contrato de seguro.

Es otro caso de nulidad relativa, asociada a la presencia de intención de fraude o dolo en el momento de la celebración de seguros coexistentes, en la medida de que, con los mismos se persiga la intención ilícita de acumular indemnizaciones en exceso del valor real del interés asegurable. En este caso la ley no impone al asegurado la pérdida de la prima pactada, aunque parece obedecer ello a un olvido involuntario, puesto que en este caso operan las mismas razones que explican la sanción en los casos anteriores.

5.- La reclamación de mala fe. Pérdida del derecho a la indemnización.

Constituye, al lado del caso del dolo en el momento de la celebración del contrato, el otro extremo usual de la presencia de dolo o mala fe del tomador del seguro dentro del marco del contrato de seguro.

La ley colombiana no exige en este caso que se configure un delito por parte del asegurado; basta que haya un obrar de mala fe, una conciencia dirigida a obtener provecho indebido, a través de conductas tales como las de exagerar la cuantía del daño, declarar destruidas cosas que no existían en el momento de la ocurrencia del siniestro, ocultar o destruir cosas que se hayan salvado, alterar las huellas y los restos del siniestro, reclamar coberturas inexistentes a sabiendas etc. Este aspecto de la relación asegurativa escapa a veces a los asegurados que pueden tener tendencia a considerar que engañar a los aseguradoras en esta etapa es una falta menor o excusable, sin imaginar la severidad del castigo que comporta no solo pérdida de los valores indebidamente reclamados, sino de la indemnización en su totalidad.

6.- La intención maliciosa del tomador al no declarar los seguros coexistentes en el momento de dar aviso de siniestro.

Esta sanción establecida en el artículo 1.076 del C. de Co. es interesante porque constituye el segundo de los tres eventos específicos de lo que nuestra doctrina denomina 
"caducidad" del contrato de seguro o pérdida del derecho a la indemnización. El primer caso es el mencionado en el numeral anterior y el tercero es el que se presenta cuando, aun sin que exista dolo por parte del asegurado, éste renuncia a los derechos contra terceros responsables frustrando de esta manera la posibilidad de subrogación del asegurador en esos derechos.

No obstante, la disposición del artículo 1.076 del C. de Co, es más una declaración hipotética que revela el interés de la ley en preservar el carácter indemnizatorio de un seguro de daños, ya que en la práctica es muy difícil, por no decir imposible que esta sanción opere en forma autónoma, puesto que supone la omisión maliciosa de la información sobre los seguros coexistentes una vez que ha ocurrido el siniestro, lo cual supone que la suma de los valores asegurados en dichos seguros coexistentes supera el valor real del interés asegurable, porque de lo contrario no podría haber intención dolosa, y es evidente que en este caso la carga del asegurado de notificar al asegurador ha surgido ya antes de la ocurrencia del siniestro por la vía del artículo 1.093 del C. de Co, y su incumplimiento tendrá el castigo que corresponde en esa etapa.

\section{7.- Los siniestros causados por dolo o culpa grave.}

Finalmente, de manera general debe señalarse otra vía de sanción del dolo del asegurado que está dada en este caso por los elementos esenciales del concepto de riesgo asegurable y por la expresa prohibición de la ley de asegurar el dolo y la culpa grave del tomador, asegurado o beneficiario del seguro en el artículo 1.055 del Código de Comercio, lo cual determina que cualquier siniestro que sea causado por dolo del asegurado o incluso por culpa grave, con la sola excepción en este caso del ramo de seguro de responsabilidad civil en el cual se admite el aseguramiento de la culpa grave, se encuentra excluido de la cobertura y, en consecuencia, se sanciona de hecho con un efecto similar al de la caducidad del contrato o pérdida del derecho a la específica indemnización en ese caso.

Debe anotarse sin embargo que existe una omisión notoria de la ley colombiana en este caso, al no señalar una sanción específica en este caso como lo hacen otras legislaciones como la española o la italiana ${ }^{1}$, toda vez que es muy distinto que no se pueda asegurar el acto meramente potestaivo o el dolo del tomador, asegurado o beneficiario y que la ley sancione con inexistencia el contrato en el que se incluye un riesgo como éste, y muy otra que en un contrato de seguro existente y válido por referirse a un riesgo asegurable, el siniestro sea causado intencionalmente por el asegurado. En este caso debería existir una sanción, se repite, específica y adecuada a la situación planteada. El Doctor Efrén Ossa ${ }^{2}$ se refiere en este caso a una exclusión de responsabilidad del asegurador "aunque no aparezca legalmente consagrada", con lo cual se manifiesta de acuerdo en la falencia del dispositivo legal específico.

Debe señalarse para terminar, como característica igualmente observable de la legislación colombiana en esta materia, la no asociación de otras sanciones por incumplimiento de cargas que corresponden a la parte asegurada dentro del contrato de

\footnotetext{
${ }^{1}$ Cfr art. 1.900 Código Civil Italiano,

${ }^{2}$ Ossa Gómez Efrén: Teoría del Seguro. Tomo II. El Contrato. Editorial Temis, Segunda edición actualizada. Bogotá, 1.991, página 470.
} 
seguro, con la mala fé de incumplido, lo que si ocurre en otras legislaciones tratándose, por ejemplo de las demoras en el aviso de siniestro o de evitar la extensión y propagación del mismo ${ }^{3}$. Es claro que las legislaciones que optan por esta vía favorecen al asegurado en la medida en que condicionan la imposición de cualquier sanción a este respecto a la demostración de mala fé, carga que por definición corresponde al asegurador. La ley colombiana al sujetar las consecuencias de dichos incumplimientos a parámetros estrictamente objetivos, es mucho más previsiva frente a eventuales comportamientos dolosos al respecto.

\section{LA PARTICULAR EXPOSICION DE LAS COMPAÑIAS DE SEGURO AL DOLO DEL ASEGURADO EN LA ACTUALIDAD.}

Resulta no obstante, de particular importancia como objeto de observación por parte de las Compañías de Seguro en la etapa actual, la situación paradójica, desde el punto de vista nuevamente de la disciplina interna propia del contrato de seguro, que en momentos en que la industria aseguradora puede verse mayormente expuesta al fraude de terceros, dados el desarrollo creciente de la influencia de las relaciones asegurativas en todo el universo de relaciones particulares, tanto comerciales como privadas, y el desarrollo de los medios técnicos y electrónicos que hacen excepcionalmente vulnerables a las grandes empresas frente a terceros de mala fé, existe por otra parte una inmensa presión por parte de las instituciones jurídicas a dotar de mayores protecciones y ventajas a los asegurados frente a la operación de las Compañías de Seguros.

La admisión primero del carácter de contrato de adhesión que tiene el contrato de seguro por vía general y la ya generalizada inclusión del contrato de seguro dentro de la órbita de las relaciones de consumo que es prácticamente un hecho indiscutible hoy, lleva en la práctica a que se considere al asegurado como un minusválido dentro de la relación asegurativa en muchos aspectos. Menesteroso de particulares necesidades de información, de claridad en los textos del contrato, de fácil lectura, de concreción y de advertencia a más de atención rápida y expedita en caso de siniestro, e irresponsable además frente a determinadas falencias en su comportamiento que el asegurador hubiera podido suplir, dentro de una particular exigencia en cuanto a su comportamiento contractual, cada vez más llamado a la excelsitud.

Esta es una tendencia universal actualmente por lo menos en los países de cultura occidental, que, no obstante justificada en gran medida dentro del contexto de las relaciones de la economía capitalista frente a la clientela corriente de las compañías, facilita claramente la actuación de quienes de mala fe pretenden defraudarlas.

Ejemplos de estas tendencias que pesan gravemente sobre las Compañías de Seguro, pueden darse, particularmente en el caso colombiano y que pueden ser extensivas igualmente a otros países, dadas las similitudes que las instituciones jurídicas presentan usualmente a este respecto, en los siguientes aspectos:

1.- La tendencia relacionada con las sanciones al asegurador por la no formulación de un cuestionario.

\footnotetext{
${ }^{3}$ Código Civil Italiano, art. 1.915.
} 
En aparte anterior, se observaba de que manera en la legislación colombiana, la regulación del artículo 1.058 del Código de Comercio, castiga de cierta manera al asegurador cuando no somete un cuestionario al tomador del seguro para orientarlo cuando procede a suministrar la información correspondiente a las circunstancias que rodean el estado del riesgo. El castigo se traduce en un aumento significativo de la carga probatoria que el asegurador tiene en cuanto a la inexactitud o reticencia, ya que en caso de no existir cuestionario el asegurador además de la realidad objetiva de la inexactitud o reticencia, debe demostrar culpa o error de conducta del tomador al incurrir en el ella.

Sin embargo nuestras disposiciones legislativas son claras en el sentido de que el no sometimiento del cuestionario al tomador del seguro, como tampoco el hecho de que no se someta a los asegurados a exámenes médicos en el caso del seguro de vida (art. 1.158 del C. de Co), no exoneran a la parte asegurada de cumplir con su carga de declarar veraz y certeramente al asegurador sobre las circunstancias que rodean el riesgo, por lo menos aquellas que con mediana diligencia y para el conocimiento normal de las personas según su grado de educación y la operación económica que desarrollan, deban entenderse significativas a este respecto. Otras legislaciones, es cierto, particularmente la española, optan por castigar de manera más severa a las aseguradoras que no proponen un cuestionario a sus asegurados, sustrayendo a éstos últimos de cualquier riesgo de impugnación del contrato por inexactitud o reticencia en la declaración del estado del riesgo cuando no son orientados en esa declaración a través de un cuestionario. ${ }^{4}$

La aplicación de una solución como la española entre nosotros no se acomoda desde luego a la realidad actual de nuestra legislación y su adopción en Colombia merecería muchos reparos de conveniencia sin duda. No obstante, existe por lo menos un antecedente en las decisiones jurisprudenciales de nuestra Corte Suprema de Justicia, que en forma por demás ligera, aunque afortunadamente dentro del limitado papel que la jurisprudencia juega como fuente de derecho entre nosotros, pretende la existencia en Colombia de un principio similar, cuando en sentencia de fecha 10 de Mayo de 1.999, con ponencia del Dr, José Fernando Ramirez, la Sala Civil de dicha corporación, sostuvo:

"Ahora es posible la contratación sin ninguna información sobre el estado del riesgo, porque no hubo declaración alguna, ni tampoco inspección, caso en el cual debe entenderse la manifestación tácita de la aseguradora de asumir el riesgo cualquiera que sea la probabilidad del daño que gravite sobre el interés asegurado. En otras palabras, en tal evento no se puede predicar nulidad por reticencia, ni mucho menos por inexactitud, ni tampoco es posible la reducción de la prestación a cargo del asegurador."

2.- No requerimiento de prueba de la cuantía de la pérdida en casos de pérdida total.

\footnotetext{
${ }^{4}$ En efecto: El artículo $10^{\circ}$. de la ley española de seguros, modificado en este punto por la ley de 21 de 19 de Diciembre de 1.990, establece: "El tomador del seguro tiene el deber, antes de la conclusión del contrato, de declarar al asegurador, de acuerdo con el cuestionario que este le someta, todas las circunstancias por el conocidas que puedan influir en la valoración del riesgo. Quedará exonerado de tal deber si el asegurador no le somete cuestionario o cuando, aún sometiéndoselo, se trate de circunstancias que puedan influir en la valoración del riesgo y que no estén comprendidas en él."
} 
Las cargas probatorias que el asegurado tiene en desarrollo del contrato de seguro, en el sentido de demostrar la ocurrencia y la cuantía del siniestro constituyen un control fundamental para el asegurador y un mecanismo importante para preservar el carácter indemnizatorio del seguro de daños. La ley desde luego, no establece ninguna excepción a este respecto en la medida de que, salvo excepciones que son siempre expresas, la declaración de valor asegurado es una declaración unilateral del asegurado sobre la cual el asegurador no tiene en la generalidad de los casos ningún control. Por lo mismo sea el siniestro total o parcial, la carga probatoria en torno a la cuantía del siniestro subsiste para el asegurado sin variación ninguna.

Por lo mismo carece de fundamento, como lo ha pregonado algún antecedente jurisprudencial, sostener que en casos de pérdida total el asegurado queda exonerado de la prueba de la cuantía del siniestro y la carga a este respecto se invierte en perjuicio del asegurador. Esto es lo que ha sostenido la sentencia de 11 de Octubre de 1.995, con ponencia del doctor Carlos Esteban Jaramillo, dentro del expediente $4470{ }^{5}$, a la cual pertenecen los siguientes apartes:

"Así las cosas, se tiene que tal como se dejó establecido en las condiciones generales aquí destacadas, de un lado, en caso de presentarse el siniestro previsto, la entidad asegurada solo estaba obligada a elevar la denuncia correspondiente y dar el aviso oportuno a la aseguradora, indicando el valor de reposición del bien asegurado, sin que puedan exigírsele requisitos adicionales, y, por otra parte, también queda claro en dichas condiciones que la suma asegurada contenida en la póliza reflejaría el valor de reposición de la máquina asegurada, es decir, el valor de adquisición de un bien nuevo de la misma clase y capacidad, y siendo que en caso de siniestro la compañía demandada, acogiendo la facultad que para pago de indemnización ofrece el artículo 1090 del Código de Comercio como excepción al valor real del interés asegurado como límite de la misma, se comprometió expresamente a reponer el bien asegurado o pagarlo en dinero en efectivo, se sigue que en este último caso estaba obligada a entregar a la sociedad contratante el valor asegurado, entendido como valor de reposición, suma respecto de la cual, después de ocurrida la pérdida total del objeto asegurado, la aseguradora no podría aducir reducción... salvo que se tratara de un supra seguro defraudatorio, pues supuesto en el cual era su cargo demostrarlo con el rigor necesario y no objetar a la ligera la reclamación de pago, apoyándose en una inteligencia acomodaticia de la póliza que la desfigura por completo."

3.- El haber debido conocer, las circunstancias en las que se hace constar la reticencia o inexactitud.

La legislación colombiana en la misma regulación del tema que tratamos, respecto a la inexactitud o reticencia en la declaración del estado del riesgo, señala que la sanción de nulidad relativa en presencia de las mismas no es aplicable "...si el asegurador, antes de

\footnotetext{
${ }^{5}$ G.J: CCXXXVII, Vol II, No. 2476, páginas 1.053 y ss.
} 
celebrarse el contrato, ha conocido o debido conocer los hechos o circunstancias sobre que versan los vicios de la declaración, o si, ya celebrado el contrato, se allana a subsanarlos o los acepta expresa o tácitamente."

Esta disposición ha llevado a la Corte Suprema de Justicia al extremo de sostener en sentencia de dos de Agosto de 2.001, con ponencia del Dr. Carlos I. Jaramillo, dentro del expediente 6146, que incluso un dolo manifiesto del tomador puede resultar excusado por una simple culpa del asegurador, que, obrando con mayor diligencia de la que utilizó en la práctica hubiese podido detectar ese dolo. A esta sentencia corresponden los siguientes apartes conclusivos:

"En efecto, al amparo de las precedentes reflexiones efectuadas en torno al fenómeno de la reticencia en el contrato de seguro y, específicamente, en lo tocante con la carga de información que, con carácter bipolar, tienen tomador y asegurador, debe colegirse que, atendidas las pruebas recaudadas, aunque es cierto que la mencionada carga para el "asegurando" no cesó en el momento en que absolvió el cuestionario de preguntas que le formuló la aseguradora en orden a determinar el estado del riesgo (julio 19 de 1993, fls. 56 y 57, cdno. 1), habida cuenta que dicha carga se extiende a todo el período precontractual, como quedó ampliamente explicado, no lo es menos que, a pesar de que aquel se enteró -el 31 de julio- de la enfermedad que padecía, antes de que la demandada aceptara su solicitud de seguro (agosto 18, fl. 63, ib.), lo mismo que de la fecha de suscripción de la póliza (agosto 25, fl. 64), la compañía, pese a esa omisión del tomador y por los datos que su propio 'agente' le había suministrado con anterioridad, bien pudo obtener esa información por otros medios, se insiste, en cumplimiento del deber de procurarse, según las circunstancias, la información necesaria para otorgar su asentimiento, motivo por el cual ella, con su actitud pasiva, dio lugar a que se materializara un conocimiento presunto que, al tenor del último inciso del artículo 1058 del Código de Comercio, ya examinado, purgó o enervó la sanción de nulidad relativa (culpa est, quod, quum a diligente provideri poterit, non est provisum), en la medida en que alertada por uno de sus médicos, quien consideró el riesgo como "No aceptable", por "obesidad y hematuria; antecedente de I.C.T.", sugiriendo la práctica de una "urografía excretora" como se indicó (fl. 58, cdno. 1), debió -en sana lógica- realizar las correspondientes indagaciones para determinar la verdadera naturaleza y estado del riesgo, pues así lo imponía el deber informativo que también recae en cabeza de la aseguradora, según se corroboró precedentemente, a fortiori, si se tiene en cuenta su insoslayable calidad de profesional, como ya se refirió, igualmente.

"Otra cosa es que esa reticencia del señor Forero no genere, en este caso en particular, la sanción de nulidad relativa, sobre la base de haber operado la excepción contenida en el inciso final del artículo 1058 del Código de Comercio, consistente en que el asegurador "ha debido conocer los hechos 0 circunstancias sobre que versan los vicios.", excepción ésta que, según fue examinado, presupone la transgresión del deber de conocer, según el caso, el estado del riesgo, o -mejor aún- de procurarse información sobre el mismo, concretamente en aquellos eventos en que tiene en su haber datos suficientes e indicativos que le permitirían, con mediana diligencia, llegar a la precisión de los hechos que el 'asegurando' deformó, 


\section{o al conocimiento que se reservó, tal y como en el sub lite aconteció, conforme lo acreditan las pruebas obrantes en el plenario."}

Hemos criticado esta doctrina de la Corte ${ }^{6}$. Es cierto que existen circunstancias que rodean el estado del riesgo que "deben ser conocidas por el asegurador" si el mismo actúa con la, diligencia profesional que le corresponde. Pero debe por ello presumir siempre que el tomador actúa de mala fe, y su diligencia profesional debe llevarlo a desconfiar de todo lo que diga el tomador para constituirse en investigador profesional de todas las artes con miras a descubrir sus falsas declaraciones.?. Y aún si llegara a establecerse una culpa del asegurador como parecía existir en el caso que se juzgó, es jurídicamente aceptable, como se ha dicho, que esa culpa tenga la virtualidad suficiente de excusar el dolo de la otra parte.

Por otro lado, y sin necesidad de las consideraciones anteriores, creemos que es este un buen ejemplo de un caso en que la teoría general del contrato en materia de vicios del consentimiento, debe ser aplicado en subsidio del especial del artículo 1.058, para el caso del dolo, que es una eventualidad no contemplada, al menos expresamente, por esta norma. Es la aplicación de esa teoría general la que impide, como se ha dicho, disculpar el dolo de una de las partes con la culpa de otra que no conoció, asi hubiera podido tener indicios del mismo, dicho dolo.

Creemos firmemente que es muy discutible que una simple culpa del asegurador pueda tener esa virtualidad. De vieja data se conoce el adagio latino "ad utroque parte dolus compendandus", esto es, el dolo de ambas partes debe compensarse, que es lo que se traduce en la fórmula del artículo 1.515 del Código Civil: "El dolo no vicia el consentimiento sino cuando es obra de una de las partes...". Es claro que si ambas partes actúan con solo, ese dolo común se compensa; pero no a la misma situación conduce el hecho de que una parte actúe con dolo y la otra con culpa. Quizás acudiendo a la asimilación que para efectos civiles se hace tradicionalmente entre la culpa grave y el dolo, que recoge el artículo 63 de nuestro Código Civil, podría en caso extremo considerarse que la culpa grave del asegurador podría excusar el dolo del tomador, sin embargo no consideramos que sea aceptable identificar el dolo con la culpa grave en aquellos casos en que no se analiza la conducta unilateral de una de las partes, sino que, por el contrario, se juzga el comportamiento recíproco de las mismas. Frente a un dolo efectivo y comprobado, la culpa del cocontratante, por grave que sea, difícilmente podría equipararse a aquel para eliminarlo, a menos que pudiera inferirse de la situación, que la culpa grave correspondiente es de tal naturaleza que prácticamente implicaba la intención de ignorar el dolo mismo como tal.

En situación igual de desconocimiento por parte del tomador y por parte del asegurador de la circunstancia que afecta el estado del riesgo y que ha sido omitida en la declaración de asegurabilidad, es lógico pensar que si el asegurador ha podido conocerla llevando a cabo determinadas pesquisas, aconsejables dentro de un criterio de mediana diligencia para un profesional en el negocio de seguros, por hechos indiciarios o indicativos que si han sido puestos en su conocimiento, no puede posteriormente alegar ese desconocimiento para eludir su responsabilidad. Pero ante la conducta intencional del

\footnotetext{
${ }^{6}$ Un comentario detallado de esta sentencia se encuentra en el Número 19 de la Revista Ibero latinoamericana de Derecho de Seguros. Páginas y ss
} 
tomador en el sentido de ocultar esa circunstancia, la situación parece bien diferente y, por lo menos, debe ser analizada con mucha rigurosidad esa especial expresión utilizada por la ley colombiana: "debido conocer" para calificar la posición eventual del asegurador frente a una reticencia o inexactitud del tomador del seguro. Esa expresión, como lo reconoce la misma Corte tiene connotaciones de mucha subjetividad y cada caso exige un análisis especial a este respecto.

Creo que en el caso que se juzgó es bien evidente que ningún asegurador hubiera consentido con un contrato de seguro de vida en las condiciones en que realmente se encontraba el riesgo y que aún de aceptarse una eventual desatención del asegurador en su consideración del examen médico practicado, los beneficiarios del seguro se lucraron en forma por demás indebida, habiéndose dado todos los efectos a un contrato que era en realidad un juego en el que una de las partes conocía claramente el resultado.

Esta doctrina jurisprudencial puede convertirse en un mensaje equívoco, en el sentido de prohijar conductas engañosas y fraudulentas de los tomadores bajo el entendido de que las mismas rendirán frutos si los aseguradores caen en el engaño o no están adecuadamente atentos al mismo.

Los dos antecedentes jurisprudenciales que se citaron en el caso, como respaldo de la decisión que se asume, no son a nuestra manera de ver pertinentes: La sentencia de 18 de Octubre de 1.995, puede mostrarse como doctrina contraria a la sentada en la sentencia que se comenta. En efecto: en el caso que se juzgó entonces, la Corte respaldó la nulidad declarada de una póliza de seguro de vida, ante el evento de una declaración inexacta del tomador en el sentido de que no había sufrido de diabetes antes del diligenciamiento del formulario, habiendo fallecido pocos meses después de otorgado el amparo por esa enfermedad. En este caso se practicaron por parte del asegurador exámenes médicos que sugerían la posibilidad de existencia de diabetes, pero la Corte consideró que como de los mismos no podía colegirse inequívocamente la existencia de la enfermedad, el incumplimiento de la carga del tomador debía entenderse probada.. En cuanto a la sentencia de 19 de Mayo de 1.999 (Expediente 4923) difícilmente podría entenderse como doctrina en el mismo sentido, en la medida de que en ese caso se trató de un seguro de crédito a la exportación en el cual se encontró demostrada igualmente una reticencia del tomador que condujo a la declaratoria de nulidad del contrato.

Es indudable pues, que por estos aspectos, la decisión de la Corte en este caso, no obstante los aportes indudables que hace al análisis de la carga de la declaración del estado del riesgo, suscita como se ya se dijo, algunos reparos que deben ser considerados.

4.- Términos cortos para contestar los reclamos y no posibilidad de pedir pruebas de que no se actúa con fraude.

Es innegable que la tendencia de la ley a hacer cada vez más corto el plazo del que dispone el asegurador, una vez recibida la reclamación del beneficiario del seguro, para tomar la decisión de pagar el siniestro u objetar dicha reclamación, si bien es una tendencia justa cuando se trata de asegurados de buena fe, por otra parte conspira a favor de los defraudadores, ya que es evidente que las aseguradoras no disponen generalmente de tiempo suficiente para acreditar la existencia de fraude cuando cuentan 


\section{REVIST@e - M ercatoria Volumen 4, Número 2 (2005)}

con términos tan exiguos para llevar a cabo las labores de investigación que son necesarias para ese efecto.

Por otro lado, a pesar de que las aseguradoras notoriamente hacen a veces innecesariamente prolongados los trámites de reclamo demandando de los asegurados informaciones que están dirigidas a establecer cuestiones totalmente diferentes a los extremos de las cargas probatorias que recaen sobre el asegurado, y que se relacionan con otras cargas totalmente diferentes, tales como las relativas al cumplimiento de las garantías, la adecuada información que debió ser suministrada en el momento de la formalización del contrato y el comportamiento del asegurado frente al siniestro antes y después de su ocurrencia, se trata de conductas que no se encuentran autorizadas por la ley. En efecto, la reclamación formal en los términos de los artículos 1.053 y 1.080 del Código de Comercio, depende exclusivamente del suministro de la prueba de la ocurrencia y de la cuantía del siniestro, por lo cual es indudable que cualquier investigación que las aseguradoras puedan adelantar con miras al establecimiento de un fraude, no tiene la virtualidad de interrumpir o suspender el término que impone la ley para la atención del reclamo, el cual debe entenderse perfeccionado independientemente de ese proceso de investigación.

Como en otros casos, este diseño legal, si bien tiende a dar protección por vía general a los asegurados de buena fe, nuevamente favorece indiscutiblemente a quienes pretenden defraudar a las Compañías.

\section{5.- La prescripción de la acción de nulidad.}

A través de las normas que regulan la prescripción de las acciones que surgen del contrato de seguro, pueden darse circunstancias propiciatorias del fraude contra las Compañías de Seguros, particularmente en aquellos casos en que esas normas facilitan de alguna manera la prescripción de las acciones de nulidad en las cuales generalmente el interesado es el asegurador y nunca o por lo menos muy raramente, el tomador del seguro.

La manera como ha quedado plasmado en Colombia el tema de la prescripción de las acciones y derechos que nacen del contrato de seguro, ha revelado una brecha manifiesta que se hizo patente en la decisión de la Sala Civil de la Corte Suprema de Justicia pronunciada con fecha 3 de Mayo de 2.000, con ponencia del doctor Nicolás Bechara, dentro del expediente $5360 .^{7}$

\footnotetext{
7 A esta sentencia corresponden los siguientes apartes: "Para los fines de la acusación que se analiza, pertinente es insistir en que las dos clases de prescripción consagradas en el artículo 1081 del Código de Comercio se diferencian por su naturaleza: subjetiva, la primera, y objetiva, la segunda; por sus destinatarios: quienes siendo legalmente capaces conocieron o debieron conocer el hecho base de la acción, la ordinaria, y todas las personas, incluidos los incapaces, la extraordinaria; por el momento a partir del cual empieza a correr el término de cada una: en el mismo orden, desde cuando el interesado conoció o debió conocer el hecho base de la acción y desde cuando nace el correspondiente derecho; y por el término necesario para su configuración: dos y cinco años, respectivamente. Síguese de lo anterior que, por tanto, no es elemento que sirva para distinguir esas dos especies de prescripción, que una y otra se apliquen sólo a ciertas acciones derivadas del contrato de seguro o de las normas que lo regulan, esto es, que la prescripción ordinaria cobre vigencia únicamente en relación con determinadas acciones y que la extraordinaria, a su paso, tenga cabida frente a otras. Como con claridad suficiente lo consagra el inciso $1^{\circ}$ del precepto que se analiza, ... Cabe
} 
En esa sentencia, con razones que son incuestionables desde el punto de vista del razonamiento jurídico ante el marco normativo planteado, dejó en claro, en primer lugar que a la prescripción de las acciones de nulidad del contrato de seguro se aplican los términos previstos en el artículo 1.081 del Código de Comercio para todos los derechos y acciones que surgen del contrato y no los términos generales señalados en los Códigos Civil y de Comercio para las acciones de nulidad que surgen de los contratos en general; en segundo lugar, estableció que transcurridos cinco años de vigencia de la póliza de seguro cualquier inexactitud o reticencia en la declaración del estado del riesgo, incluso las de carácter doloso, se sanean por efecto de la prescripción de la acción de nulidad que, a juicio de la Corte, comporta igualmente la imposibilidad de proponer por parte del asegurador la excepción de nulidad.

Con esa decisión la Corte hace especial hincapié en la inaplicabilidad en el caso colombiano del principio de la imprescriptibilidad de las excepciones que era la circunstancia que las Compañías de Seguro tenían generalmente presente como una seguridad en el sentido de que, en cualquier caso, la nulidad del contrato podía ser alegada por ellas en cualquier tiempo, en caso de que el beneficiario de una póliza de seguro adelantara en su contra una acción dirigida a cobrar la indemnización en caso de siniestro.

Si bien la aplicabilidad del artículo 1.081 del Código de Comercio a la acción de nulidad del contrato de seguro, beneficia a las aseguradoras en la medida en que por lo menos contra ellas el término de prescripción ordinaria de la acción de nulidad, que es apenas de dos años, no comienza a correr en su contra sino a partir del momento en que tienen conocimiento de la inexactitud o reticencia en las que ha incurrido el tomador del seguro, la decisión de la Corte de considerar no aplicable el principio general de no prescriptibilidad de las excepciones en este caso si las afecta fundamentalmente, en la medida en que, como ya se dijo, el dolo de un asegurador puede resultar saneado por la

afirmar, entonces, que todas las acciones de que se trata son susceptibles de extinguirse ya sea por prescripción ordinaria, ora por prescripción extraordinaria, y que, por tanto, la aplicación de una y otra de esas formas de prescripción extintiva depende de la persona que ejerza la respectiva acción o intente la efectividad de algún derecho y de la posición que ella tenga en relación, precisamente, con el hecho que motive la acción o con el derecho que persigue. ... Fluye de lo anterior, por consiguiente, que fue errada la inteligencia que el Tribunal de Medellín dio a la disposición objeto de estudio, ... es decir, al vincular la acción dirigida a obtener el reconocimiento y pago de un siniestro exclusivamente con la prescripción extraordinaria. Es que, como viene de apuntarse, tanto en el caso de la acción intentada con la demanda principal (cobro de primas) como en el de la ejercida por el inicial demandado en la demanda de reconvención (cobro de la prestación asegurada), la prescripción extintiva operante es, en principio, la ordinaria, por ser sus titulares personas capaces que, en su momento, conocieron o debieron conocer el hecho provocante de su acción, esto es, el no pago oportuno de las primas y la objeción que al monto del reclamo efectuado por razón del memorado siniestro hicieron las compañías aseguradoras. ... Si ello es así, la errada interpretación que el Tribunal dio al tantas veces invocado artículo 1081 del Código de Comercio, sólo adquiere trascendencia frente a las determinaciones consistentes en la desestimación de la excepción de prescripción que las aseguradoras formularon ante la demanda de reconvención y, por contera, en el acogimiento de la acción ejercitada mediante dicho libelo por el primigenio demandado, por cuanto el estudio de ese mecanismo defensivo y, por ende, de si la acción se había o no extinguido, debía hacerse a la luz de la prescripción ordinaria, y no de la extraordinaria, como con desacierto lo estimó el ad - quem." 
vía de una prescripción de término relativamente corto, lo cual, dentro del contrato de seguro resulta particularmente contraindicado dada la relativa facilidad con la que el fraude puede ser consumado dentro del marco de este contrato y dado también el particular margen de beneficio económico que puede significar para un tomador de mala fe la circunstancia de ser el contrato de seguro un contrato aleatorio.

Por otro lado, debe tenerse en cuenta que la aplicabilidad sin excepción del artículo 1.081 del Código de Comercio a la acción de nulidad derivada del contrato de seguro, lleva a que también la nulidad absoluta del contrato en virtud de causales generales, tenga un término de prescripción muy corto frente al término que opera en el caso de otros contratos, que es de diez años conforme a la reforma establecida en el artículo 1․ de la ley 791 de 2.002, y aún a que pueda igualmente plantearse una discusión en torno al posible saneamiento, por prescripción de cinco años, de la nulidad derivada de objeto o causa ilícita en el contrato de seguro, no obstante la disposición contenida en el artículo 1.742 del C. C. ${ }^{8}$

El Doctor Jorge Eduardo Narváez ${ }^{9}$ ha hecho una crítica muy interesante con la perspectiva del derecho constitucional a esta sentencia de la Corte, con la óptica de que es inaceptable concluir que un término de prescripción pueda comenzar a contarse sin que interesado conozca la existencia del hecho en el que puede fundar su demanda, e insinúa que en este caso ha podido existir una inapropiada acomodación de la legislación francesa a la ley colombiana en materia de prescripción de las acciones y derechos que emanan del contrato de seguro. En efecto, en la legislación francesa ${ }^{10}$, desde la ley de 1.930, la prescripción de dos años de las acciones que emanan del contrato de seguro se cuenta por regla general desde la ocurrencia del hecho generador, pero, cuando se trata de la acción de nulidad del contrato de seguro por inexactitud o reticencia en la declaración del estado del riesgo, se establece una excepción expresa en el sentido de que en este caso la prescripción de la acción no puede comenzar a contarse sino desde el momento en que el interesado conoce la existencia de dichas inexactitud o reticencia; pero en este caso la ley francesa es solo un desarrollo de las normas generales sobre prescripción de la acción de nulidad de los negocios jurídicos en general, puesto que en Francia un viejo principio del Código civil establecido en el artículo 1.304 de ese estatuto señala que en los casos de error o dolo, la prescripción de las acciones de nulidad solo comienza a contar desde el momento en que los mismos son conocidos por el contratante inocente. En Colombia existe un principio diferente; el artículo 1.750 del Código Civil expresamente establece que la prescripción de la acción de nulidad en los casos de error y dolo, comienza a contar desde la fecha de realización del contrato.

\footnotetext{
${ }^{8}$ No obstante esta observación la hacemos simplemente para indicar la necesidad de una claridad expresa a este respecto, toda vez que en nuestra opinión la norma del Código Civil a este respecto debe considerarse aplicable al caso del contrato de seguro.

9 Narváez Jorge Eduardo: "El Contrato de Seguro en el Sector Financiero". Ediciones Librería del Profesional. Primera edición, Bogotá, 2.002. Paginas 348 y ss.

${ }^{10}$ Picar y Besson: "Les assurances terrestres" Tome I, 4a. Edition, L.G.D.J, Paris 1.975, páginas 258 y 259.
} 
6.- La causación de intereses de mora desde el momento de la presentación de la demanda.

Puede también mencionarse como un elemento que puede servir de estímulo a los defraudadores de las Compañías de Seguro, la inexplicable doctrina de la misma Sala Civil de la Corte Suprema de Justicia, que se ha constituido en la ventaja más inesperada para los asegurados que resuelven eludir el trámite normal de la reclamación directa de la indemnización al asegurador, procediendo en forma directa al proceso judicial en su contra.

Conforme a esa doctrina, en este caso, de ser vencida la Compañía de Seguros en el proceso, el establecimiento de la mora del asegurador y la consecuente causación de los intereses de mora o de la indemnización correspondiente a los perjuicios que pueda probar el asegurado como consecuencia de ella, se hacen exigibles y comienzan a causarse desde el mismo momento de la notificación de la demanda.

Esta sentencia parte de la base de la aplicabilidad al caso del contrato de seguro de la regla establecida en el inciso $2^{\circ}$. del artículo 90 del C. de P.C conforme al cual: " La notificación del auto admisorio de la demanda en procesos contenciosos de conocimiento produce el efecto del requerimiento judicial para constituir en mora al deudor, cuando la ley lo exija para tal fin, si no se hubiere efectuado antes". Sin embargo, la decisión ignora el hecho de que en materia de seguros, existe una norma especial y por consiguiente de aplicación preferente, que es la contenida en el artículo 1.080 del Código de Comercio, conforme a la cual la mora del asegurador depende en todos los casos de que se formalice el reclamo judicial o extrajudicial por parte del beneficiario del seguro, reclamo que como ya se ha dicho antes, debe necesariamente incorporar el cumplimiento de la carga probatoria que incumbe a la parte asegurada dentro del contrato de seguro. Ahora bien, esto no es caprichoso, porque la demostración de la ocurrencia y de la cuantía del siniestro a la que solamente tiene acceso directo el asegurado, es un presupuesto necesario para que el asegurador pueda ser considerado punible de retardo en el pago de la indemnización.

Por lo mismo, carece de todo fundamento pretender que con la sola notificación de una demanda, sin que se haya surtido la actividad probatoria ni antes ni después de la misma, pueda configurarse la mora del asegurador. En caso de una reclamación judicial cuando, o no se ha formulado reclamación extrajudicial o ésta no ha sido perfeccionada, la mora solo puede producirse en el momento de la sentencia, o, en el mejor de los casos, en el momento en que culmine dentro del proceso es debate probatorio, puesto que solo entonces podrá entenderse cumplido el requisito señalado por el artículo $1.080 \mathrm{del} \mathrm{C}$. de Co.

Si bien es cierto que podría decirse que esto sucede cuando el asegurador es vencido en el proceso, y que en consecuencia en estos casos está descartado el dolo del asegurado, bien sabemos que ello no es así siempre y que la proverbial dificultad de la prueba del dolo es un problema que afecta indiscutiblemente a las Compañías de Seguro en general frente a los defraudadores y que se ve inmensamente agravado, cuando se establece una ventaja tan sustancial a quienes precisamente eluden la etapa de reclamación directa que priva al asegurador de una instancia muy importante para investigar e identificar un caso eventual de fraude. 
7.- La responsabilidad de las Compañías asociada a la responsabilidad de los intermediarios.

Otra circunstancia que puede concurrir a facilitar el fraude contra las aseguradoras, es sin duda alguna la defectuosa legislación existente en torno a las labores de intermediación en materia de seguros. Particularmente es conocida la ambigüedad que proverbialmente ha existido en cuanto al carácter representativo de las agencias colocadoras de seguros que es extensiva a los denominados agentes independientes.

Normas puntuales del estatuto orgánico del sistema financiero, del decreto 2605 de 1.993 y recientemente de la ley 510 de 1.999, han insistido tercamente en asignar un carácter representativo por vía general a las agencias colocadoras de seguro respecto de las aseguradoras, y sin embargo otras disposiciones del mismo estatuto orgánico establecen un inventario de facultades mínimas que no implican verdaderamente representación, sino quizás tan solo para efectos de recibir las primas pagadas por los tomadores. De hecho, las aseguradoras solo excepcionalmente conceden a las agencias y, en general a los intermediarios de seguros facultades representativas para otros efectos y casi nunca para los únicos que entrañarían verdaderamente una representación efectiva en cuanto a los negocios de seguros se refiere, que son los correspondientes a la celebración del contrato o a la realización o aceptación de ofertas.

La atribución por vía legal de facultades representativas a las agencias colocadoras de seguros que no se acomodan realmente a la voluntad que preside la celebración de los contratos que se suscriben con dichos auxiliares del mercado asegurador, ni a la manera como las Compañías entienden la labor de los mismos, permite que pueda llegar a concluirse que esta clase de intermediarios están facultados para ejecutar actos y negocios jurídicos que sobrepasen las facultades mínimas que señala la ley, incluida la celebración del contrato de seguro; por otro lado, que los errores y culpas en los que incurran las agencias, en desarrollo de sus labores con un marco ampliado significativamente, comportan responsabilidad de los aseguradores y, particularmente, que cualquier acto de mala fe en el que incurran al ocultar al asegurador circunstancias que lleguen a conocer acerca del estado del riesgo o al asesorar inadecuadamente a los tomadores del seguro sobre la manera de informar sobre dichas circunstancias, impida a los aseguradores cualquier alegación en torno a la presencia de inexactitudes o reticencias en la declaración del estado del riesgo. ${ }^{11}$

Esta ambigüedad en el tratamiento legal ha dado lugar a decisiones jurisprudenciales que sugieren y exponen claramente el peligro al que se encuentran abocadas las aseguradoras a este respecto, y aconsejan que se lleve a cabo un vigoroso esfuerzo para que se defina de manera clara desde el punto de vista legislativo, la naturaleza de los contratos que vinculan a las partes que intervienen en la celebración del contrato de seguro con los intermediarios que frecuentemente actúan dentro del proceso de negociación y, en especial, que, como es usual en otras legislaciones, se establezca una diferencia clara entre los intermediarios que actúan con facultades representativas reales

\footnotetext{
${ }^{11}$ Este tema se estudia a espacio en el texto del artículo del mismo autor denominado: "La responsabilidad de los intermediarios de seguros", ponencia presentada en el XXIII Encuentro Nacional de Acoldese reunido en Barraquilla en Octubre de 2.004, que se publicará en Memorias próximas a aparecer.
} 
para celebrar el contrato de seguro a nombre de cualquiera de las partes y los que se limitan a promover el contrato como fuerza de ventas de las compañías.

8.- La Aplicación indiscriminada al contrato de seguro de los principios de protección propios de las relaciones de consumo y, en especial del estatuto del consumidor cuyo proyecto se encuentra en discusión en las cámaras legislativas en este momento.

Este solo punto daría para consideraciones muy extensas; para los efectos de este análisis, el comentario debe limitarse a señalar que existen razones para sustraer al contrato de seguro de algunas reglas que son usuales en las legislaciones modernas de protección al consumidor, que dentro del proyecto que se estudia en Colombia van a ser copiadas. Aunque el análisis debe hacerse punto por punto, lo cierto es que, respecto del contrato de seguro actúan dos circunstancias que son particulares frente a otro tipo de contratos que se celebran entre empresas y usuarios o consumidores, que han justificado tradicionalmente un tratamiento específico: una es la circunstancia de ser el contrato de seguro un contrato aleatorio, dentro del cual existe una expectativa de prestación económica a favor del asegurado que es muy superior a la erogación que supone a su cargo el pago de la prima; la otra es la particular protección que se da al asegurado normalmente a través de normas imperativas de la ley que en gran medida regulan los aspectos fundamentales de la disciplina privada del contrato, a lo cual se agregan el control estatal que es ejercido a través de la Superintendencia bancaria sobre los modelos de las pólizas de seguro y las tarifas, y las particulares obligaciones que se imponen al asegurador en torno a la información que debe suministrar al asegurado previamente a la celebración del contrato.

Esas circunstancias deben exigir una atención especial, cuando se trata de aplicar, como ya se dijo, el régimen de protección al consumidor, a la relación asegurativa. Ejemplos de cláusulas que no son permitidas usualmente en la relaciones generales con consumidores y que deben ser aplicables a nuestro juicio al contrato de seguro, pueden ser, entre otras, las que autorizan la cesión del contrato por parte del proveedor, cuando no hay consentimiento del usuario o las que no obstante ser desfavorables al asegurado han sido negociadas expresamente; por otro lado, los mecanismos que desarrollan la teoría de los "productos o servicios defectuosos" dentro del marco de la relaciones de consumo, no deben ser aplicables indiscriminadamente al contrato de seguro, en la medida en que se viole el principio de la selección de riesgos que proverbialmente existe a favor del asegurador dentro del contrato de seguro.

\section{INSTRUMENTOS EFECTIVOS DE LUCHA CONTRA EL FRAUDE QUE HAN SIDO} DESARROLLADOS JURISPRUDENCIALMENTE:

\section{1.- La contabilidad fraudulenta o irregular.}

Un importante elemento en la lucha contra el fraude, en cambio, han sido las decisiones adoptadas por la Corte Suprema de Justicia en lo que se refiere a la ineptitud de la contabilidad irregularmente llevada por el asegurado, para sustentar la prueba de la cuantía de las pérdidas determinadas por un siniestro. 
Dentro de estas decisiones debe destacarse la sentencia proferida con fecha 21 de Marzo de 2.003, con ponencia del Magistrado Cesar Julio Valencia Copete, dentro del expediente 6642, a la cual corresponden los siguientes apartes:

"En compendio, si lo que muestra el proceso es que para acreditar el monto de la mercancía el Tribunal otorgó valor probatorio -por medio de los dictámenes periciales, un documento y un testimonio- a unos libros indebidamente llevados, cuando lo cierto es que las probanzas mencionadas $y$, principalmente, las experticias, en últimas, se apoyaron en una contabilidad incompleta, no se remite a duda que el sentenciador incurrió en error de derecho al no percatarse que, frente a semejante irregularidad, la prueba resultaba convicta de ineficacia, al tenor del artículo 271 del Código de Procedimiento Civil.

En este preciso sentido se ha pronunciado la Corte:

"Son dos los motivos legales de ineficacia probatoria de los libros de comercio: la doble contabilidad o fraude similar y la contabilidad irregularmente llevada. En ninguno de los dos casos los libros prueban a favor.

"La doble contabilidad, o fraude similar, suponen la existencia de una contabilidad para engañar a terceros, que puede estar regularmente llevada, es decir acomodada formalmente a los requisitos legales, pero que no obstante resulta ineficaz, por ocultar las operaciones verdaderas. La contabilidad irregular por su lado también es ineficaz, por no ajustarse a las formalidades legales, así refleje operaciones verdaderas. "(G. J. t, CCXII, pag. 202).

El supuesto que ahora se presenta es el último, dado que la contabilidad era incompleta, habida cuenta que no todas las operaciones de compra o venta de mercancías llevadas a término por la sociedad eran registradas en los libros, situación que, a todas luces, riñe con los propósitos que aquella debe cumplir y con los requisitos que el ordenamiento impone, en especial, si se recuerda que los artículos 48 y 50 del Código de Comercio perentoriamente prevén que la contabilidad debe suministrar una historia clara, "completa" y fidedigna de los negocios del comerciante, no siendo dable hacerlo por partes, como aquí ocurrió. Por tanto, si en este caso la contabilidad desatendía las exigencias legales, se produjo su ineficacia probatoria, con independencia de la veracidad o no de los datos incorporados en ella.

Ciertamente, el concepto al que arribaron los auxiliares de la justicia contraria el contenido de las otras pruebas que militan en el proceso, puesto que, de la manera como se dejan examinadas, éstas conducen a la inequívoca conclusión de que los libros de comercio se llevaban indebidamente, lo cual, como se dijo, viene a generar la pérdida de su fuerza probatoria, apreciación que arrasa de paso con la fundamentación de las experticias, más aún, porque siendo este punto del debate un asunto estrictamente jurídico - la regularidad de los libros de comercio -, su definición concierne privativamente al fallador.

La opinión de los peritos, ha expresado la Sala, no "obliga en sí mismo y por sí sola" (G.J. t. LXXI, pag. 375), como tampoco su existencia en el interior del proceso 
determina, per se, su forzosa admisión por parte del juzgador, por cuanto ella siempre estará sometida a la seria evaluación de éste, quien ha de tener en cuenta los aspectos contemplados en el artículo 241 del estatuto procesal civil, para determinar libre y exclusivamente el mayor o menor grado de convencimiento que le asigna para la demostración del hecho o hechos en cuestión. En otras palabras, lo ha esbozado esta Corporación, el juez no está "forzado nunca a admitirlo o rechazarlo mecánica o ciegamente" (G.J. t, LVII, pag. 532), ni siquiera en el evento de faltar solicitud de aclaración o por no haber sido materia de objeción, pues ello equivaldría suponer que correspondiera a los peritos reemplazar al juez en su misión de sentenciar.

El anterior razonamiento viene a propósito de la falta de acogimiento por la Corte del trabajo de los expertos, así estos señalaran que "... la información contable que nos permite hacer una valuación de los inventarios, está soportada en libros legalmente registrados y soportados con sus respectivos comprobantes de contabilidad" (C 2, fl. 13), en el primer concepto y, en el segundo, que "la contabilidad es llevada de acuerdo con las normas de contabilidad generalmente aceptadas y llevada en forma regular "(C. 2, fl. 84), cuando, como quedó visto, de las evidencias resaltadas se desprende justamente lo contrario."

La trascripción anterior, no obstante su extensión, es importante para destacar de qué manera la Corte no sólo establece con claridad la ineficacia de la doble contabilidad y de la contabilidad irregularmente llevada como medio para demostrar la cuantía de las pérdidas que alega haber tenido el asegurado como consecuencia de un siniestro, sino que afirma igualmente la impropiedad en la conducta de los ajustadores y de los peritos, al deducir una cuantía con base en esos elementos y al hacer afirmaciones que riñen con la realidad objetiva en el momento de elaborar sus informes, impropiedad que conduce a que los mismos no sean desde luego obligatorios para el fallador en instancia judicial.

2.- La validez de la cláusula contractual que excluye la cobertura en los seguros de automóviles de aquellos que no han sido legalmente importados al país o que han sido objeto de delitos contra el patrimonio de las personas.

En sentencia de 21 de Mayo de 2.002, con ponencia del Dr. Silvio Fernando Trejos, dentro del expediente No. 7288, la Sala Civil de la Corte Suprema de Justicia definió acertadamente la validez de la cláusula contractual que excluye la cobertura de vehículos "Cuando el vehículo haya sido ingresado al país de contrabando, o no esté matriculado de acuerdo con las normas de tránsito o haya sido objeto material de un ilícito contra el patrimonio de las personas, antes de asegurarse, sean estas circunstancias conocidas 0 no previamente por el tomador, asegurado o beneficiario sin importar que estos hayan participado o no en tales hechos", conforme a las siguientes consideraciones:

"En la especie de este proceso, ciertamente que la demandada asumió el riesgo de hurto de un vehículo que no estuviera envuelto en situaciones irregulares precedentes constitutivas de un ilícito o que se hubieran presentado en perjuicio de terceros, las que de darse no quedaba cubierto aquel ni ningún otro amparo, lo cual a la luz de la norma citada, corresponde a un pacto válido y a una conducta correcta y, por tanto, libre de reproche, mucho más si en cumplimiento de claros preceptos legales que hoy rigen la actividad aseguradora la cláusula de exclusión aparece en 
la póliza no solo adelante, sino en caracteres visibles para el tomador. ... Con todo, en desarrollo de esa función activa no se halla facultado el sentenciador para obrar a su antojo, ni para dejar sin efecto previsiones de orden contractual en las que, aun dispuestas bajo el concepto de condiciones generales, las cuales, por serlo, corrientemente escapan a un análisis previo y detallado de quien se adhiere a ellas, si tampoco aflora la intención del otro sujeto contratante de sustraerse al cumplimiento de sus obligaciones cuando sea la oportunidad de acatarlas; en particular, le está vedado al fallador, so capa de obrar en equidad, erradicar la convención o una de sus cláusulas a fuer de sobreponer principios que, como el de la buena fe, no habilitan, per se, para obrar de ese modo.

Con esa fórmula de exclusión la compañía aseguradora pactó una cláusula de contenido netamente objetivo, en el cual la buena fe de las partes no tuvo injerencia, razón por la cual no contraviene los principios generales del derecho ni las normas de orden público"

Esta decisión de la Corte Suprema de Justicia, resulta de gran importancia, dada la gran cantidad de casos que se han detectado dentro del mercado nacional, de redes delincuenciales que buscan legalizar el producto de delitos relacionados con automotores como el robo y el contrabando, a través del aseguramiento de los mismos y del cobro de indemnizaciones correspondientes a través de la simulación de siniestros, particularmente el de robo. Es de advertir que el uso de la cláusula contractual por parte de las Compañías de Seguro, se hizo necesario ante el hecho de que la tendencia generalizada en las decisiones de los jueces de instancia, era la de considerar que no existiendo dicha cláusula en los contratos y no demostrándose la mala fe del último adquirente, no era posible que el asegurador negara a éste la indemnización correspondiente en caso de siniestro, basada en la simple alegación de existir objeto o causa ilícitos en el contrato de seguro.

Pero, adicionalmente, en el caso que se juzgó, la Corte sale al paso de la tesis sostenida por el Tribunal de instancia, conforme a la cual, no obstante la presencia de la cláusula así concebida en el contrato, la misma no podía tener eficacia frente a la buena fé del último adquirente del vehículo.

3.- La validez de la cláusula contractual que consagra como garantía dentro del contrato de seguro de trasporte, expedido bajo la forma de póliza automática, la carga por parte del asegurador de notificar al asegurador de todos los despachos en los que llegue a adquirir interés asegurable dentro del periodo de vigencia de la póliza.

La Corte también ha salido al paso de decisiones de instancia por parte de Tribunales Superiores de Distrito Judicial que han pretendido negar validez o eficacia a las cláusulas de garantía que, en las pólizas automáticas de seguro de trasporte establecen esta carga para el asegurado.

Es así que en sentencia de 30 de Septiembre de 2.002, con ponencia del Doctor Carlos Ignacio Jaramillo, la Corte sostuvo la validez de este tipo de cláusulas frente a la posición asumida por el Tribunal en el sentido de que " al tenor del artículo 1061 del C. de Co., la garantía puede ser o no sustancial con respecto al riesgo, pero debe existir conexidad entre ellos, de tal manera que su no cumplimento haga menos controlable el riesgo, "su 
incumplimiento debe significar un incremento de probabilidad de ocurrencia del siniestro o del daño que de él dimana." ... "El hecho de que sean menos los despachos asegurados no puede significar un incremento de probabilidad de ocurrencia del siniestro o de incremento del daño que de él dimana". Este argumento fue suficiente consideración para que el Tribunal de instancia despachara negativamente la excepción propuesta por el asegurador de "terminación del contrato" anterior a la ocurrencia del siniestro, por incumplimiento de la garantía.

La Corte sostuvo en este caso que si bien la garantía debe tener relación con el riesgo, no necesariamente debe vincularse directamente con su intensidad o probabilidad, de allí que el artículo 1.061 del Código de Comercio pregone que las garantías deben ser cumplidas "sean o no consubstanciales al riesgo", lo cual permitió salvar el derecho del asegurador en este caso a dar por terminado el contrato ante la violación de la garantía, frente a lo que es una actitud de evidente mala fe por parte de cualquier asegurado en la póliza automática, que se limita a dar aviso de los Despachos de mercancía que son afectados por un siniestro, lo cual no puede traducirse sino en perjuicio económico para el asegurador y en inaceptable ventaja para el asegurado.

\section{ESFUERZOS QUE DEBEN HACERSE EN EL FUTURO:}

Para terminar, no sobra hacer alusión a dos ramos del seguro que se enfrentan actualmente a una compleja problemática relacionada con el fraude y que demandan en el caso colombiano una atención, a nuestra manera de ver particular. Nos referimos a los ramos de seguro de vida individual y al ramo de cumplimiento.

En el primer caso, existen alarmas que provienen de fuentes diversas, sobre la proliferación de los casos de aseguramiento de la vida de indigentes con fines de especulación criminal, que han puesto en evidencia la insuficiencia de los múltiples mecanismos que prevé la regulación comercial para impedir este tipo de conductas. Particularmente en este aspecto se hace necesario que los aseguradores redoblen sus esfuerzos y los de su fuerza de ventas para ejercer controles sobre la situación financiera de sus asegurados en el ramo de vida individual, a fin de impedir que se sigan sucediendo estos casos.

En el caso del seguro de cumplimiento la problemática puede abordarse en dos aspectos: En primer lugar, en el caso de los seguros de cumplimiento de contratos entre particulares, es indudable que se trata de un ramo que es particularmente susceptible a casos de connivencia entre los contratantes para defraudar a los aseguradores, por lo cual se impone igualmente una labor preventiva particularmente cuidadosa. En segundo lugar, en el campo de los seguros de cumplimiento de contratos estatales, aunque en este caso no se puede hablar expresamente de fraude, si creemos que las compañías de seguros, con el objeto de preservar el normal desarrollo de los negocios en este ramo, deben hacer un esfuerzo para que la jurisdicción contencioso administrativa haga conciencia de que las tendencias que vienen adoptando las sentencias del Consejo de Estado en torno a las garantías de cumplimiento de contratos estatales, en el sentido de que las entidades públicas aseguradas pueden proceder al cobro de los valores asegurados en las pólizas, mediante la simple expedición de actos unilaterales que declaran la ocurrencia del siniestro y sin que haya lugar a demostrar los perjuicios que efectivamente han sufrido con ocasión de incumplimiento del contratista, constituyen un 


\section{REVIST@e - M ercatoria Volumen 4, Número 2 (2005)}

abierta e inconveniente violación del carácter indemnizatorio de un seguro de daños, como lo es sin duda el seguro de cumplimiento, y estimulan conductas arbitrarias por parte de las entidades públicas que implican beneficio económico indebido desde todo punto de vista para las mismas. 